\title{
Investigation of coal-associated bacterial and archaeal populations from a diffusive microbial sampler (DMS)
}

\section{Authors: Elliott P. Barnhart, Kara Bowen De Leóna, Bradley D. Ramsay, Alfred B. Cunningham, \& Matthew W. Fields}

NOTICE: this is the author's version of a work that was accepted for publication in International Journal of Coal Geology. Changes resulting from the publishing process, such as peer review, editing, corrections, structural formatting, and other quality control mechanisms may not be reflected in this document. Changes may have been made to this work since it was submitted for publication. A definitive version was subsequently published in International Journal of Coal Geology, 115, August 2013. DOI\#10.1016/j.coal.2013.03.006.

Barnhart EP, De León KB, Ramsay BD, Cunningham AB, Fields MW, "Investigation of coalassociated bacterial and archaeal populations from a diffusive microbial sampler (DMS)," International Journal of Coal Geology, August 2013 115:64-70. 


\title{
Investigation of coal-associated bacterial and archaeal populations from a diffusive microbial sampler (DMS)
}

\author{
Elliott P. Barnhart a,b, Kara Bowen De León a,b Bradley D. Ramsay ${ }^{\mathbf{b}}$, \\ Alfred B. Cunningham $b, c$, Matthew W. Fields $a, b, d, e, *$ \\ a Department of Microbiology, Montana State University, Bozeman, MT, United States \\ b Center for Biofilm Engineering, Montana State University, Bozeman, MT, United States \\ c Department of Civil Engineering, Montana State University, Bozeman, MT, United States \\ d Thermal Biology Institute, Montana State University, Bozeman, MT, United States \\ e National Center for Genome Resources, Santa Fe, NM, United States \\ A B S T R A C T
}

Keywords:

Coal

Biofilm

Natural gas

Methane

Powder River Basin deposits with biologically generated coal bed methane (CBM). The microbial ecology of an area within a coal bed influenced by recent groundwater recharge was sampled with a diffusive microbial sampler (DMS). The DMS contained native coal material and was incubated in situ $(57 \mathrm{~m}$ depth) to allow colonization of the coal particles. Pyrotag sequence analyses of SSU rRNA gene sequences from the coal contained within the post-incubation DMS detected methylotrophic and hydrogenotrophic methanogenic archaea along with diverse bacterial communities. Microbial enrichments (coal or acetate/H2) were established from the DMS, and the enriched bacterial and archaeal communities were characterized via clone library analysis. The in situ bacterial communities were more diverse than the archaeal communities, and the archaeal populations differed between coal incubated in situ and in laboratory enrichments. In addition, bacterial diversity was higher for laboratory enrichments with coal compared to enrichments without coal. The elucidation of rela-tionships between microorganisms involved in coal degradation and metabolite (acetate, $\mathrm{H}_{2}$ ) utilization within coal-dependent microbial communities is crucial to understanding and improving in situ coal bed methane production.

I N T R O D U C T I O N

Energy sources with low carbon emissions, such as methane gas, are becoming increasingly important with climate change and rising energy needs worldwide. Subsurface coal, a difficult substrate for microorganisms to utilize due to recalcitrant properties, has been asso-ciated with vast methane deposits within coal beds (Strąpoć et al., 2011). In some areas, the methane gas from the coal beds can be produced and utilized as an industrial energy source. Estimates of recov-erable CBM (coal bed methane) from the Powder River Basin (PRB) in southeastern Montana and northeastern Wyoming vary, but with cur-rent extraction techniques an estimated 17.4 trillion cubic feet (TCF) could be recoverable (Meredith et al., 2012). This reserve is substan-tial considering 1 TCF of methane could supply the natural gas needs of 400,000 households for 20 years (Bauder, 2007). However, little is known about the methanogenic microbial communities responsible for producing the methane, the coal bed conditions that contribute to methane production, or the key microbial community interactions that contribute to coal-dependent methanogenesis. Methane production in coal beds is the consequence of a series of metabolic interactions among various groups of microorganisms (Strąpoć et al., 2011). Molecular techniques have been applied to coal bed microbial systems in an attempt to detect dominant microbial community members present in produced water and coal core sam-ples (Fry et al., 2009; Jones et al., 2010; Li et al., 2008; Midgley et al., 2010; Penner et al., 2010; Shimizu et al., 2007; Strąpoć et al., 2008). These studies suggest that coal beds are generally colonized by an array of bacterial populations that commonly include members of the Proteobacteria (Li et al., 2008; Midgley et al., 2010; Penner et al., 2010; Shimizu et al., 2007). Archaea have also been detected in several core and water samples originating from coal beds at a much lower diversity compared to that of bacteria (Green et al., 2008; Klein et al., 2008; Li et al., 2008; Midgley et al., 2010; Penner et al., 2010; Shimizu et al., 2007; Strąpoć et al., 2008). Several models have been proposed which hypothesize the microbial interactions resulting in the microbial breakdown of coal to produce methane. Under low redox conditions, the primary fermentation of polymers and monomers 
to fatty acids, organic acids (e.g., lactate, succinate, acetate), alcohols (e.g., methanol), hydrogen, and carbon dioxide is carried out by fermentative bacteria (Strąpoć et al., 2011). The primary fermentation products can be utilized by both Bacteria and Archaea including: secondary fermenting bacteria (syntrophs); homoacetogenic bacteria; and acetoclastic, methylotrophic, and hydrogenotrophic methanogens (Strąpoć et al., 2011). Trace elements have also been shown to impact methane production and methanogen abundance in microcosms inoculated with produced water from the PRB (Unal et al., 2012).

Trace elements and nutrients enhancing the conversion of organic matter within coal beds to methane are basically derived from two different sources in situ: nutrients supplied from the substratum sediments and nutrients from the groundwater recharge. In general, groundwater of the PRB flows from the south towards the northeast and low-transmissivity shale layers common in the PRB isolate the water from other aquifers providing very long flow paths that are dominated by hydrogenotrophic methane production $\left(\mathrm{CO}_{2}+\right.$ $4 \mathrm{H}_{2} \Leftrightarrow \mathrm{CH}_{4}+2 \mathrm{H}_{2} \mathrm{O}$ ) (Bates et al., 2011; Flores et al., 2008; Meredith et al., 2012; Rice et al., 2008). Several areas of groundwater recharge occur along the western margin of the PRB where the coal seams outcrop, especially near the Montana-Wyoming border (Bates et al., 2011; Rice et al., 2008). Isotopic evidence within this recharge area indicates that acetoclastic or methylotrophic methanogenesis is dominant in situ $\left(\mathrm{CH}_{3} \mathrm{OO}^{-}+\mathrm{H}^{+} \Leftrightarrow \mathrm{CH}_{4}+\mathrm{CO}_{2}\right)$ (Bates et al., 2011; Flores et al., 2008; Rice et al., 2008). To further investigate the in situ processes mediating acetoclastic or methylotrophic methane production, we utilized a novel sampling technique to gain insight into the microbial ecology present in a well near a recharge area along the western margin of the PRB (GWIC 8430) (Bates et al., 2011).

A significant amount of research has been dedicated to understanding the in situ microbial system involved in converting subsurface coal to methane (Guo et al., 2012; Jones et al., 2010; Midgley et al., 2010; Penner et al., 2010; Strąpoć et al., 2008; Unal et al., 2012). Such studies have relied on traditional formation water and/or coal core samples to access the coal-utilizing microbial community. Research suggests that groundwater samples do not reflect microbial densities and activities in the subsurface (Alfreider et al., 1997; Penner et al., 2010). In addition, core samples are prohibitively expensive to obtain and difficult to collect aseptically. Down-well incubation of sterile substrate has emerged as an alternative method for sampling subsurface microorganisms (Alfreider et al., 1997; Griebler et al., 2002; Peacock et al., 2004; Reardon et al., 2004). A down-well incubation technique was utilized in the present study with a diffusive microbial sampler (DMS) with modifications to only expose the sediment within the inner part of the DMS at the bottom of the well to target coal-utilizing microbial populations.

In this study, we aimed to enhance the fundamental understanding of the ecology and physiology of methane-producing, coal-associated communities, and to identify microbial community responses to laboratory enrichment conditions that included coal and several metabolites (acetate, $\mathrm{H}_{2}$ ) suspected to form when coal is degraded by Bacteria (Jones et al., 2010; Strąpoć et al., 2011). This analysis allowed new insight into the in situ microbial community and populations involved in coal degradation and metabolite utilization.

\section{Methods and materials}

\subsection{Sampling site}

The study site was located in southeastern Montana in the CX field where significant groundwater recharge occurs from areas several miles away in the Wolf Mountains and further from the BigHorn Mountains with flow moving east at a calculated rate of $80 \mathrm{ft} / \mathrm{yr}$ (Bates et al., 2011; Wheaton and Donato, 2004). Well WR-53A is a monitoring well used by the Montana Bureau of Mines and Geology to monitor the effect of methane development on regional groundwater tables. The well was drilled in 1977 to a depth of $57 \mathrm{~m}$, sealed with a packer from $38.7 \mathrm{~m}$ to $41.8 \mathrm{~m}$ and screened from $42.7 \mathrm{~m}$ to the bottom (57 m). Complete geochemical analysis, site location and well logs can be obtained at the Montana Bureau of Mines and Geology Groundwater Information Center (GWIC) website: http://mbmggwic.mtech.edu with GWIC ID 8430.

A diffusive microbial sampler (DMS) was designed to colonize native coal material with an indigenous microbial consortium from Powder River Basin (PRB) coal seams. The DMS consisted of a cylinder ( 2.5 in. diameter and $5 \mathrm{in}$. long) with 2 rods extending from the top of the cylinder to a weight $12 \mathrm{in}$. below the cylinder. The weight sealed the DMS, due to gravity, until contacting the bottom of the well where the rods extending from the weight lifted the coal out of the sealed cylinder allowing colonization by indigenous microorganisms. Sediment within the sampler was composed of approximately $25 \mathrm{~g}$ of sub-bituminous coal particles ( $>2 \mathrm{~mm}$ but $<4 \mathrm{~mm}$ diameter) from the Decker Coal Mine in the Powder River Basin (PRB) several miles from well WR-53A. The coal particles were encased with \#8 stainless steel mesh. The DMS was autoclaved prior to being placed in the well allowing autoclaved coal to act as the negative control in our DNA analysis. The DMS was retrieved from well WR-53A using aseptic techniques after three months of incubation. There was not a noticeable loss of coal from the sampler during the time of incubation.

\subsection{Microbial enrichments}

Three $\mathrm{ml}$ of slurry from the DMS was immediately added to anaerobic coculture medium (CCM) after retrieval from the bottom of the well. The CCM contains $30 \mathrm{mM}$ sodium acetate and (per liter) $2.17 \mathrm{~g} \mathrm{NaCl}, 5.5 \mathrm{~g} \mathrm{MgCl}_{2} \cdot 6 \mathrm{H}_{2} \mathrm{O}, 0.14 \mathrm{~g} \mathrm{CaCl}_{2} \cdot 2 \mathrm{H}_{2} \mathrm{O}, 0.5 \mathrm{~g} \mathrm{NH}_{4} \mathrm{Cl}$, and $0.335 \mathrm{~g} \mathrm{KCl}$ and is buffered with $1.1 \mathrm{mM} \mathrm{K}_{2} \mathrm{HPO}_{4}$ and $30 \mathrm{mM}$ $\mathrm{NaHCO}_{3}$. One ml per liter of $1000 \times$ nonchelated trace elements and $1 \mathrm{ml}$ per liter of $1000 \times$ vitamin solution amended with $2.0 \mathrm{~g} / \mathrm{l}$ choline chloride were added as growth supplements as previously described (Walker et al., 2009). L-cysteine $\cdot \mathrm{HCl}(1 \mathrm{mM})$ and sulfide $(1 \mathrm{mM}$ as $\left.\mathrm{Na}_{2} \mathrm{~S} \cdot 9 \mathrm{H}_{2} \mathrm{O}\right)$ were added as reducing agents. Resazurin $(1 \mathrm{mg} / \mathrm{l})$ was added as a redox indicator. Stock solutions of $\mathrm{K}_{2} \mathrm{HPO}_{4}(1 \mathrm{M}), \mathrm{NaHCO}_{3}$ (6.0 M), L-cysteine $\cdot \mathrm{HCl}(1 \mathrm{M}), \mathrm{Na}_{2} \mathrm{~S} \cdot 9 \mathrm{H}_{2} \mathrm{O}(1 \mathrm{M})$, and the nonchelated trace element and vitamin mixtures were prepared under anoxic conditions as previously described (Walker et al., 2009). Coal remaining in the DMS was immediately frozen on dry ice and transported to a $-80{ }^{\circ} \mathrm{C}$ freezer and stored until used for DNA analysis.

Methane production from laboratory cultures was monitored by direct injection on a SRI 8610C gas chromatograph (GC) with a thermal conductivity detector (TCD) and a stainless-steel molecular sieve $13 \times$ packed column with helium as the carrier gas. After methane production was detected in the enrichments inoculated from well WR-53A, liquid coal slurry was transferred to fresh CCM medium with $5 \mathrm{~g}$ coal added with a $\mathrm{CO}_{2}$ headspace or $30 \mathrm{mM}$ sodium acetate along with an 80:20 $\mathrm{H}_{2} / \mathrm{CO}_{2}$ headspace. The enrichments were incubated in the dark at $25{ }^{\circ} \mathrm{C}$ and methane production was monitored via GC.

\subsection{DNA extraction}

DNA was extracted from the coal from the DMS sampler, coal cultures and acetate $/ \mathrm{H}_{2}$ cultures. DNA was extracted at the same time point for the coal cultures and acetate $/ \mathrm{H}_{2}$ cultures. Approximately $0.5 \mathrm{~g}$ of coal from the DMS was aseptically placed in a $1.5 \mathrm{ml}$ tube with $1 \mathrm{ml}$ of $10 \%$ SDS. The samples were heated to $70{ }^{\circ} \mathrm{C}$ for $15 \mathrm{~min}$ followed by a vortex pulse to suspend the coal and another $15 \mathrm{~min}$ at $70{ }^{\circ} \mathrm{C}$ to wash the microorganisms off the coal. Microbial biomass was retrieved from the cultures by filtering the medium through a $0.2 \mu \mathrm{m}$ filter and both the filter and the coal were included in the DNA extraction. Total community DNA was extracted using the BIO 101 FAST DNA spin kit (MP Biomedical, Solon, $\mathrm{OH}$ ) according to the 
manufacturer's instructions with the following modifications: DNA bound to the silica matrix was allowed to settle for $30 \mathrm{~min}$, and the spin filter was allowed to air-dry in a biosafety cabinet for $30 \mathrm{~min}$ following the salt-ethanol wash. In order to account for heterogeneity in community diversity and structure as well as variability in DNA extraction efficiency, the culture was extracted in triplicate. Autoclaved coal was extracted alongside the samples and used as a negative control.

\subsection{Pyrotag analysis}

Pyrosequencing was used to characterize the bacterial and archaeal populations from the DMS. Nested archaeal and semi-nested bacterial PCR amplification were performed to increase the concentration of DNA for pyrosequencing analysis. The thermal profile used in bacterial PCR reactions included initial denaturation at $94{ }^{\circ} \mathrm{C}(2 \mathrm{~min})$; followed by 25 cycles of denaturation at $94{ }^{\circ} \mathrm{C}(30 \mathrm{~s})$, annealing at $58{ }^{\circ} \mathrm{C}$ ( $1 \mathrm{~min}$ ), and primer extension at $72{ }^{\circ} \mathrm{C}(1 \mathrm{~min})$; and a final extension at $72{ }^{\circ} \mathrm{C}$ for $7 \mathrm{~min}$. The final reaction mixture $(20 \mu \mathrm{l})$ contained $10 \mu \mathrm{l}$ $2 \times$ EconoTaq PLUS (Lucigen, Madison, WI) and $1.0 \mu \mathrm{M}$ of each of the forward and reverse primers along with 5-10 $\mu$ g template. Each sample was amplified with a unique 10 -nt barcode to enable multiplexing. The bacterial primers included: barcoded FD1 (5'-AGAGTTTGATCCTG GCTCAG-3') and non-barcoded 1540R (5'-GGAGGTGWTCCARCCGC-3') in the initial amplification and barcoded FD1 and barcoded 529R (5'-GGCAGATTCTTTGCCTTCTG-3') in the second round of amplification (Bowen De León et al., 2012; Yakimov et al., 2001). The archaeal primers included: 21F (5'-TTCYGGTTGATCCYGCCRGA-3') and 1492R (5'-CGGTT ACCTTGTTACGACTT-3') and barcoded 751F (5-'CCGACGGTGAGRGRYG AA-3') and 1204R (5-TTMGGGGCATRCIKACCT-3') (Baker et al., 2003). A $0.8 \%$ agarose gel in TAE buffer was used to check the PCR products for DNA of the correct size. The gel extracts were cleaned and concentrated using the Wizard SV Gel and PCR Cleanup System ${ }^{\circledR}$ (Promega, Madison, WI), and dsDNA was quantified with a Qubit fluorometer (Life Technologies, Carlsbad, CA, USA). Adaptors for 454 sequencing were ligated to the amplicons and were pyrosequenced in a Roche 454 GS-Junior (454 Life Sciences, Branford, CT, USA). The barcoded sequencing reads were separated by Roche's image analysis and sequence assignment software providing high confidence in assigning sequencing reads to the appropriate sample. Sequences were trimmed to one standard deviation below the mean length (removed if shorter), and subjected to a Phred score filter allowing $15 \%$ of the nucleotides to be below Q27, and removed if primer errors or Ns were observed. Forward reads were carried through the analysis. A python script was used for data management and analysis as previously described (Bowen De León et al., 2012). Chimeras were removed using ChimeraSlayer (Haas et al., 2011). The Michigan State University Ribosome Database Project Pyrosequencing Pipeline (http://pyro.cme.msu.edu) was used to align sequences, complete-linkage clustering at $97 \%$ similarity, and to calculate Chao1 indices. Sequences were identified with a Basic Local Alignment Search Tool (BLAST) search against the National Center for Biotechnology Information (NCBI) nucleotide (nr/nt) database.

\subsection{Clone library analysis}

Clone library analysis was utilized to investigate the archaeal and bacterial populations contained within the enrichment cultures. Approximately 2.0-2.5 ng of DNA was used to perform PCR with universal bacterial primers FD1 and 1540R, universal archaeal primers $21 \mathrm{~F}$ and $1492 \mathrm{R}$ (sequences above) and mcrA specific forward primer, 5'-GGTGGTGTMGGATTCACACARTAYGCWACAGC-3', and a reverse primer, 5'-TTCATTGCRTAGTTWGGRTAGTT-3' (Luton et al., 2002). The thermal profile used in the bacterial PCR reaction included initial denaturation at $94{ }^{\circ} \mathrm{C}(2 \mathrm{~min})$; followed by 30 cycles of denaturation at $94{ }^{\circ} \mathrm{C}(30 \mathrm{~s})$, annealing at $58{ }^{\circ} \mathrm{C}(1 \mathrm{~min})$, and primer extension at $72{ }^{\circ} \mathrm{C}(1 \mathrm{~min})$; and a final extension at $72{ }^{\circ} \mathrm{C}(7 \mathrm{~min})$. The thermal profile used in the archaeal PCR reaction included: initial denaturation at $94{ }^{\circ} \mathrm{C}$ ( $5 \mathrm{~min}$ ); followed by 25 cycles of denaturation at $94{ }^{\circ} \mathrm{C}$ (30 s), annealing at $55{ }^{\circ} \mathrm{C}(30 \mathrm{~s})$, and primer extension at $72{ }^{\circ} \mathrm{C}$ ( $2 \mathrm{~min})$; and a final extension at $72{ }^{\circ} \mathrm{C}(7 \mathrm{~min})$. The final reaction mixture $(20 \mu \mathrm{l})$ contained $10 \mu \mathrm{l} 2 \times$ EconoTaq PLUS (Lucigen, Madison, WI) and $1.0 \mu \mathrm{M}$ of each of the forward and reverse primers. A $0.8 \%$ agarose gel in TAE buffer was used to check the PCR products for DNA of the correct size. Bands were excised and cleaned using the Wizard SV Gel and PCR Cleanup System ${ }^{\circledR}$ (Promega Inc., Madison, WI) according to the manufacturer's instructions (Promega Inc., Madison, WI). Cleaned products were cloned using the Invitrogen PCR2.1-TOPO vector according to the manufacturer's instructions (Life Technologies, Carlsbad, CA). Archaeal and bacterial clones (192 each) were picked based on blue/white screening for selection of recombinants and submitted for sequencing to Functional Biosciences (Madison, WI) using Sanger sequencing methods with bacterial primer 529R (sequence above) archaeal primer 519R (5'-ACAATGTCATTGGTCAATTCATT-3') and $m c r A$ /M13R, (5'-CAGGAAACAGCTATGACCTTCATTGCRTAGTTW GGRTAGTT-3'). Sequences were extracted from chromatograms using BioEdit (http://www.mbio.ncsu.edu/BioEdit/bioedit.html) and aligned, clustered and dereplicated using the RDP pyrosequencing pipeline as described above. Dereplicated sequences were identified using the BLASTn algorithm by NCBI (http://ncbi.nlm.nih.gov).

\section{Results}

\subsection{Pyrotag sequence analysis of in situ community}

A total of 6144 archaeal sequence reads with 74 operational taxonomic units (OTU) and 5339 bacterial sequence reads with 407 OTUs were obtained through pyrotag analysis after trimming and qualitychecking the sequences. The average read lengths were 380 and 365 bases for archaea and bacteria, respectively. The OTUs were defined with 3\% dissimilarity and analyzed with Chao1 diversity estimates (Chao and Lee, 1992; Hughes et al., 2001). Chao1 statistical analysis suggested that further sequencing of the microbial community would lead to additional unique OTUs and reveal more genera/species although the majority of the estimated diversity was sampled (Table 1). To illustrate in detail the composition of the communities detected with this analysis, each OTU, along with its putative identity and corresponding percent similarity has been provided in Supplementary Table 1.

\subsection{Microbiota observed with pyrotag analysis}

All of the archaeal sequences sampled from the DMS could be classified as closely related to the hydrogenotrophic methanogen, Methanobacterium (58.7\%), or the methylotrophic methanogen, Methanolobus (41.3\%) (Mochimaru et al., 2007) (Supplementary Table 1). The detected bacterial community was very diverse and approximately $33 \%$ of the bacterial sequence reads belonged to the phylum Proteobacteria (32.6\%) with the dominant class being $\beta$-Proteobacteria. The phyla Actinobacteria (29.8\%), and Firmicutes (21.0\%) were also predominant and represented a large portion of the sequence reads. Interestingly, a significant portion (almost 16\%) of the sequences detected in the analysis was most closely related to phototrophic cyanobacteria and chloroplast sequences (Fig. 1 and Supplementary Table 1). Phototrophic

\section{Table 1}

Summary of reads, operational taxonomic units (OTUs), diversity and richness estimates of pyrotag analysis.

\begin{tabular}{|c|c|c|c|c|c|c|}
\hline \multirow[t]{2}{*}{ Sample } & \multicolumn{3}{|c|}{ Archaea } & \multicolumn{3}{|c|}{ Bacteria } \\
\hline & Reads & OTUs $^{\mathrm{a}}$ & Chao1 & Reads & OTUs $^{a}$ & Chao1 \\
\hline WR-53A & 6144 & 75 & $\begin{array}{l}82 \\
(77,107)^{b}\end{array}$ & 5339 & 407 & $\begin{array}{l}587 \\
(524,684)^{b}\end{array}$ \\
\hline
\end{tabular}

a The operational taxonomic units (OTU) were defined with $3 \%$ dissimilarity.

b $95 \%$ confidence intervals for Chao1 estimators. 

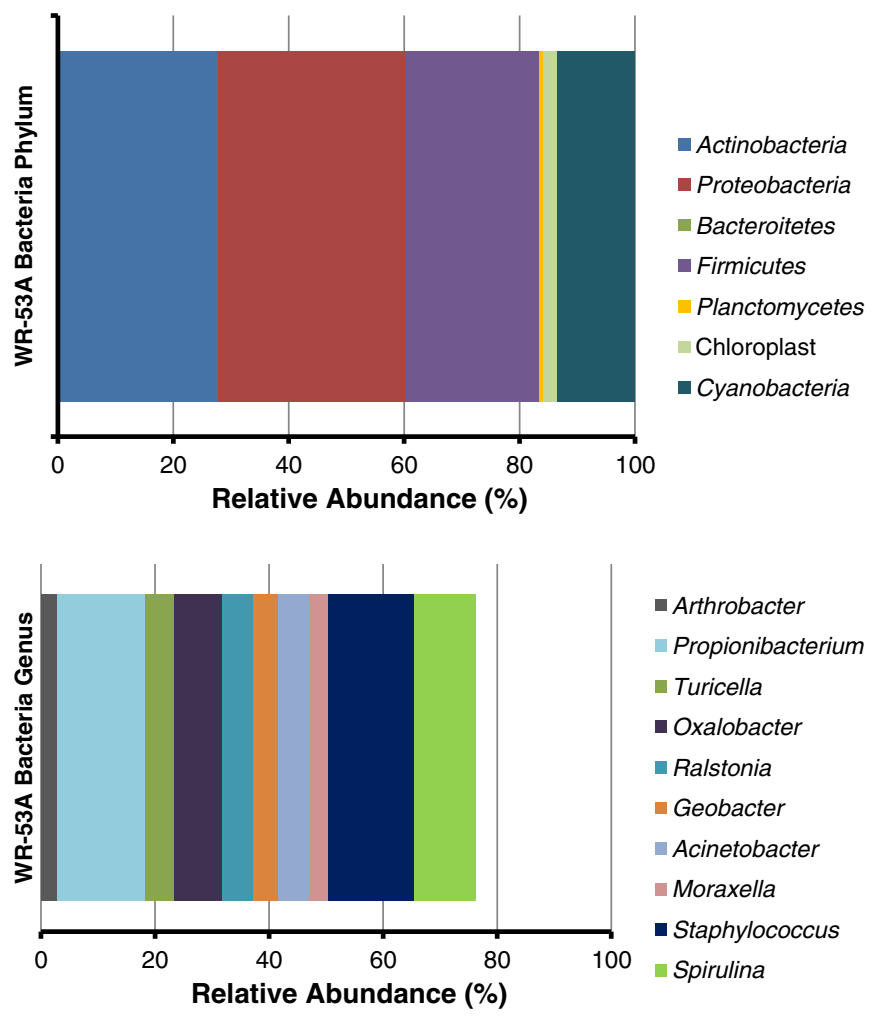

Fig. 1. Phylogenetic classification by phylum and the top 10 genus for the bacterial pyrotag analysis from coal incubated in the DMS at site WR-53A.

organisms and/or biomass could be carried into the subsurface environment with recharge water and may represent a source of allochthonous carbon and nutrients.

\subsection{Coal-dependent microbial communities}

A total of 83 bacterial clones (SSU rDNA gene sequences) from the coal culture and 85 bacterial clones from the acetate $/ \mathrm{H}_{2}$-amended culture (no coal) were sequenced (Fig. 2). The bacterial diversity was greater in the coal enrichment compared to the acetate $/ \mathrm{H}_{2}$ enrichment: 24 versus 8 OTUs at the genus level. An OTU closely related (98-100\% sequence identity) to the SSU rRNA gene sequence of Acetobacterium, a homoacetogen, comprised approximately 25\% of both libraries (Eichler and Schink, 1984). The three next most abundant OTUs in the coal enrichment were most closely related to Acetivibrio (97-99\% sequence identity), Clostridium (84-98\% sequence identity), and Desulfovibrio (98\% sequence identity). Other OTUs detected in the coal but not acetate $/ \mathrm{H}_{2}$ enrichment included Aminobacterium, Geobacter, Herbaspirillum, Spirochaeta, and Synotrophus.

The archaeal diversity was lower compared to the bacterial diversity and only 3 unique OTUs were detected at the genus level for either enrichment (coal or acetate $/ \mathrm{H}_{2}$ ) (Fig. 3). The acetate $/ \mathrm{H}_{2}$ enrichment was predominated by Methanosarcina (86\%), Methanospirillum (13\%), and Methanosaeta (1\%). The coal enrichment was predominated by multiple Methanosarcina groups (91\%) and a Methanospirillum group (9\%). Similar results were observed when mcrA diversity was compared between the coal- and acetate/ $\mathrm{H}_{2}$-enrichments (data not shown).

\section{Discussion}

High-throughput 454 pyrotag analysis was utilized to investigate the in situ microbial communities. Pyrotag analysis is widely accepted and has been used to investigate the microbial ecology in a vast number of diverse habitats, such as a biogas plant (Schlüter et al., 2008), deep mines (Edwards et al., 2006), the deep marine biosphere (Huber et al.,
2007) and subsurface coal beds in China (Guo et al., 2012). It should be acknowledged that all PCR-based methods are not without potential bias due to differing DNA extraction efficiencies and bias of primer selectivity. Because of the difficulty of extracting DNA from coal, we used nested and semi-nested PCR in this study, which has also been necessary in other microbial coal bed investigations (Guo et al., 2012; Klein et al., 2008).

Based on the results from 454 pyrosequencing, both hydrogenotrophic and methylotrophic methanogens were present in situ. OTUs related to Methanolobus and Methanobacterium have been recently detected with pyrotag analysis from subsurface coal beds in China (Guo et al., 2012). The presence of these methanogenic sequences was not unexpected based on isotopic data indicating that both $\mathrm{CO}_{2}$-reduction and methyl-type fermentation played major roles in gas generation near this site (Flores et al., 2008). This isotopic data cannot distinguish between acetoclastic methanogenesis and methylotrophic methanogenesis; however, our data indicate methylotrophic instead of acetoclastic methanogenic populations predominate in situ in this area of the basin as Methanolobus spp. can utilize methanol as a substrate for methanogenesis rather than acetate. Interestingly, sequences indicative of these organisms were not detected in the enrichments from the DMS, and instead sequences indicative of the genera Methanosarcina, Methanosaeta, and Methanospirillum were detected. Methanosarcina spp. are the only identified methanogens which possess all three known pathways for methanogenesis (acetoclastic, methylotrophic and hydrogenotrophic) (Galagan et al., 2002). Methanosaeta spp. are limited to acetoclastic methane production while Methanospirillum spp. are limited to $\mathrm{H}_{2}$ and $\mathrm{CO}_{2}$ for methane production. It is common for molecular-based and cultivation-based methods to detect different populations, and our results highlight the limitations of cultivation-based methods to indicate active populations in situ. However, given the right conditions (i.e., higher environmental acetate concentrations), the acetoclastic methanogens identified in the enrichments may dominate in situ under stimulated conditions. Further work is needed to accurately assess active microbial populations that contribute to in situ methanogenesis under different conditions.

The bacterial community detected with 454 pyrotag analysis was diverse but most of the bacterial sequence reads (32\%) belonged to the phylum Proteobacteria as previously observed in other CBM basins (Guo et al., 2012; Midgley et al., 2010; Penner et al., 2010; Shimizu et al., 2007). The dominant class of Proteobacteria was $\beta$-Proteobacteria that consists of populations with hydrocarbon-degrading capabilities (Rotaru et al., 2010). Oxalobacter which are known for anaerobically breaking down oxalate as a source of energy and carbon for cellular biosynthesis (Jonsson et al., 2004) was a top $\beta$-Proteobacterial genus detected in the pyrotag analysis (Fig. 1). Researchers have performed aqueous extractions of different ranks of coals and oxalate was the most prevalent extracted anion from low-rank coals which is the predominant coal in the Powder River Basin (Bou-Raad et al., 2000). Although some inferences can be made about significant microorganisms from pyrotag analysis, molecular biology techniques can be combined with enrichment studies to begin to understand the physiological and biochemical bases of coal-based methanogenesis and the relevant microorganisms involved in the conversion of coal to methane (Strąpoć et al., 2011).

The DMS was raised and used to inoculate anaerobic media with different amendments (i.e., coal or acetate/ $\mathrm{H}_{2}$ ). Methane production was monitored and clone libraries were used to determine predominant differences in community composition and structure related to coal-dependent methane production. The DNA was extracted from the enrichment cultures with significant methane concentrations at the same time point (150 days), and other researchers have shown that different microbial clades associated with methane production dominate at various time points during batch culturing (Jones et al., 2010). At 150 days the coal-only enrichments had 3-fold higher bacterial SSU rRNA gene sequence diversity compared to the acetate/ $\mathrm{H}_{2}$ 


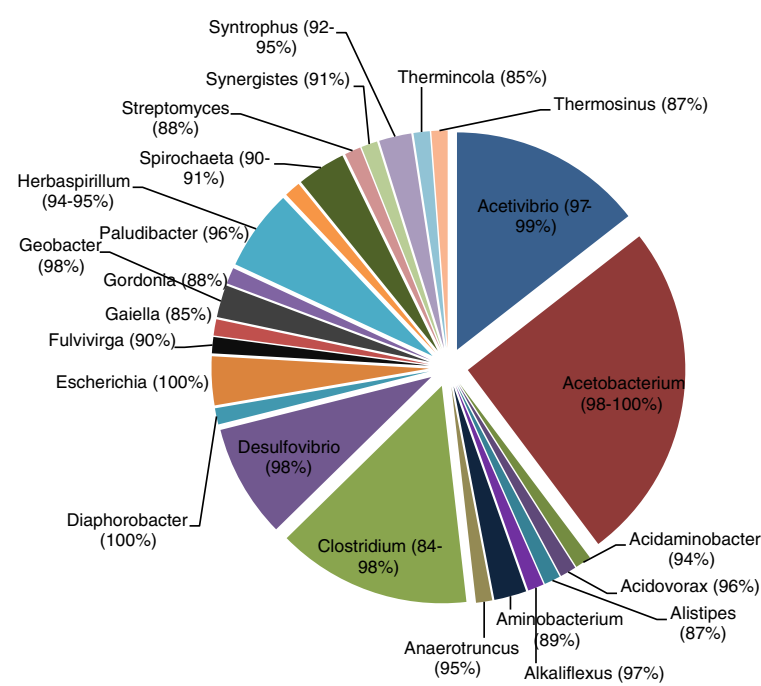

Coal

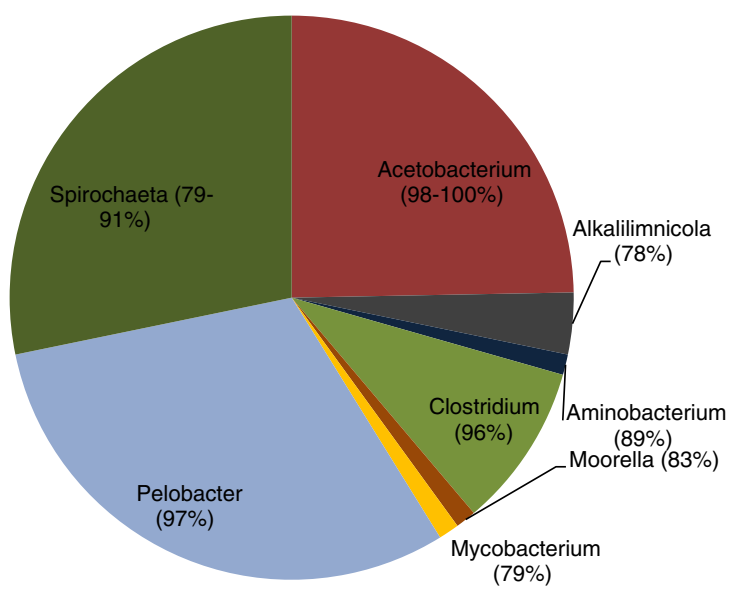

Acetate/H2 (no coal)

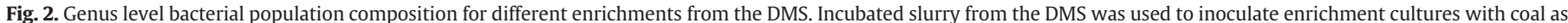

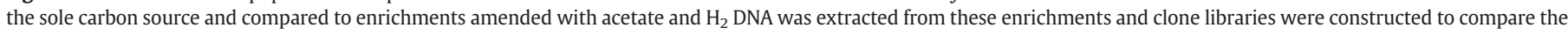

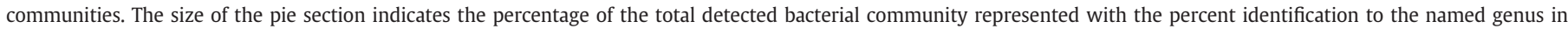
parentheses.

culture ( 24 versus 8 OTUs at the genus level). Based upon enrichment cultures, coal promoted bacterial diversity and the diversity of bacterial populations may play an important role in efficient coal-degradation (i.e., due to the heterogeneous nature of coal polymers). The presence of sequences indicative of homoacetagens suggests potential competition between acetogens and hydrogenotrophic methanogens for $\mathrm{H}_{2}$ and that indirect shuttling of reductants from fermenters to acetoclastic or methylotrophic methanogens may go through homoacetogens.

In order to understand the relationship between communities identified by the enrichment and in situ analysis, we compared their community profiles with the pyrotag analysis obtained from the original DMS sample. The Venn diagram (Fig. 4) categorizes the overlap of the detected bacterial phyla in all three samples: WR-53A, coal enrichment and metabolite (acetate, $\mathrm{H}_{2}$ ) enrichment. Based on the sampled diversity, the Actinobacteria, Proteobacteria, Bacteriodetes, and Firmicutes phyla were observed in all three samples and no phyla were detected in the metabolite enrichment that was not observed in the other samples. Several phyla were only observed in the coal and metabolite enrichments and not in the environmental sample (WR-53A) indicating they may have been rare in the in situ community and below the

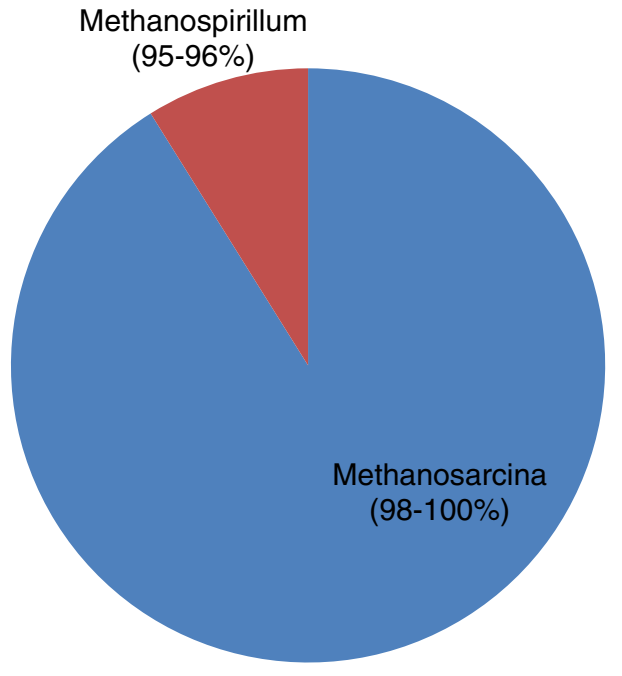

Coal

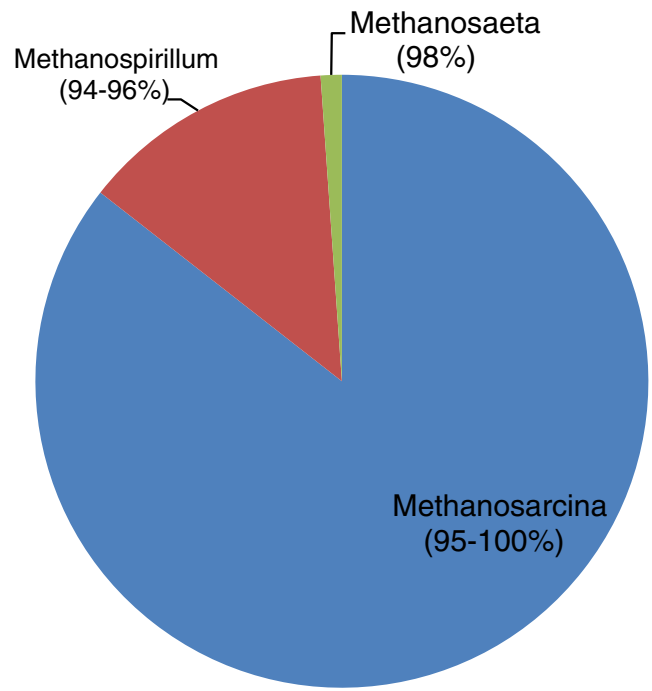

Acetate $/ \mathrm{H}_{2}$ (no coal)

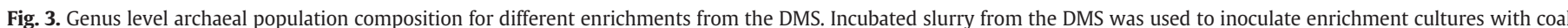

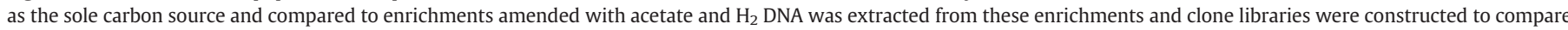

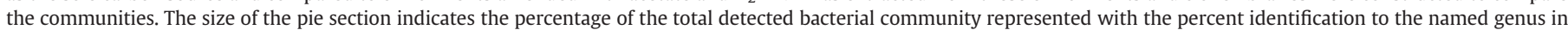
parentheses. 


\section{WR-53A}

Coal

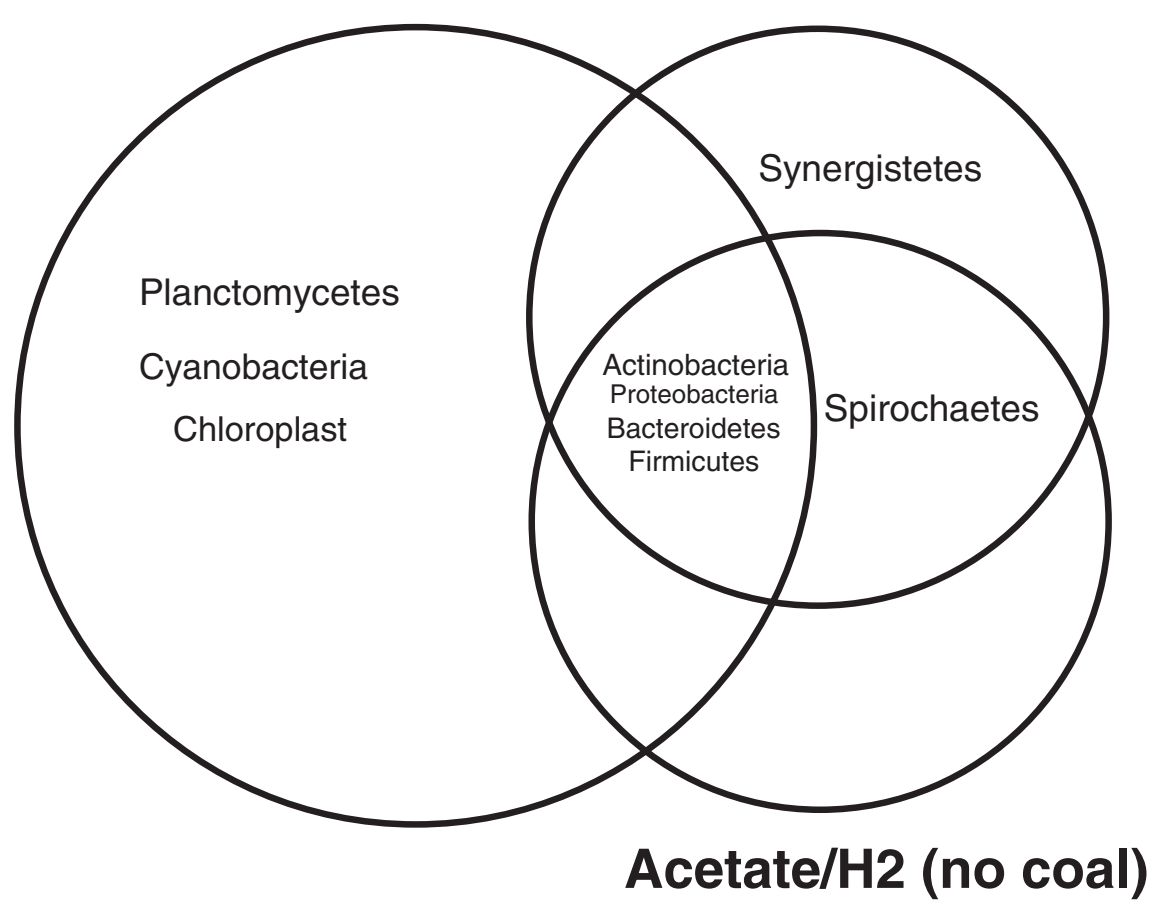

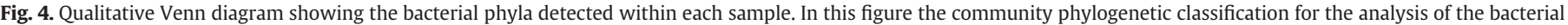

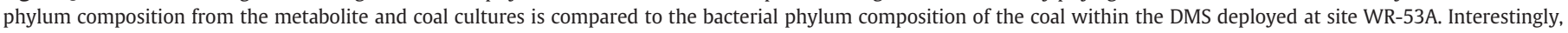

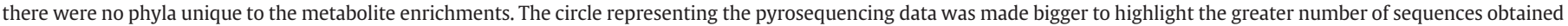
compared to the clone libraries.

detection limit but could still play an important role in coal degradation or metabolite utilization given the right conditions. The Spirochaetes phylum was shared only between the metabolite enrichment and the coal enrichment. Spirochaetes have been studied for over 100 years for their role in termite gut biota resulting in methane production (Breznak, 2002). Spirochaetes species are capable of obtaining energy for growth by $\mathrm{H}_{2} / \mathrm{CO}_{2}$-acetogenesis, i.e., $4 \mathrm{H}_{2}+2 \mathrm{CO}_{2} \rightarrow \mathrm{CH}_{3} \mathrm{COOH}+2$ $\mathrm{H}_{2} \mathrm{O}\left(\Delta \mathrm{G}^{\circ}=-105 \mathrm{~kJ}\right.$ per mole acetate) (Leadbetter et al., 1999). Synergistetes were only observed in the coal enrichment sample indicating that they also were minor components in the environmental sample (WR-53A) but may also be important players in coal degradation when the right conditions are present. Bacteria within the phylum Synergistetes have recently been observed to compete for acetate with acetate-utilizing methanogens (Ito et al., 2011).

Microorganisms belonging to the phyla Planctomycetes and Cyanobacteria were only detected in the environmental sample along with microorganisms most closely related to eukaryotic chloroplast sequences indicative of algae. The abundance of the sequences related to Cyanobacteria suggests that biomass may have been transported into the subsurface with the groundwater recharge and not a remnant of contamination introduced when the well was drilled in 1977. It is possible that re-charge and/or slow turnover of microbial biomass (e.g., DNA) could explain the observed cyanobacterial sequences. The major recharge areas are miles away and with a calculated flow rate of $80 \mathrm{ft} /$ year, DNA from these phototrophic microorganisms would have to remain in subsurface for many years in order to reach the area where well WR-53A is located (Wheaton and Donato, 2004). Alternatively, clinker ridges and the Anderson coal bed outcrop close to the CX field, could supply a smaller amount of recharge but allow for a shorter travel distance (Van Voast and Thale, 2001; Wheaton and Donato, 2004). Future research is needed to fully understand the presence of these sequences at the site.

\section{Conclusion}

There is currently a great deal of interest as to what extent the in situ microbial conversion of coal into methane can contribute towards satisfying the growing energy needs of the United States as more sustainable and renewable sources are developed. The useful life of a CBM well, on average, is currently less than ten years (Meredith et al., 2012). Therefore, stimulation of the methane-producing community contained within the coal beds is required for sustainable development of domestic resources. We investigated the microbial ecology of an area within the PRB that appears to have been naturally stimulated with groundwater recharge. A novel sampling technique was utilized that was successful in capturing a microbial community consistent with the previous isotopic data retrieved from the area. Pyrotag analysis indicates organisms capable of methylotrophic and hydrogenotrophic methanogenesis dominate the archaeal community within well WR-53A while the bacterial community was diverse. In order to better understand the individual groups of archaea and bacteria involved in coal degradation and metabolite utilization, enrichment techniques were combined with molecular biology methods to infer potentially important organisms involved in producing acetate and/or $\mathrm{H}_{2}$ from coal and microorganisms that utilize the metabolites. Within the enrichments, coal appeared to maintain bacterial diversity compared to enrichments with $\mathrm{H}_{2}$ and acetate. Nearly twenty-five percent of the bacterial OTUs from the WR-53A environmental sample had a low similarity (less than $90 \%$ identity) to any known cultured bacteria published on the NCBI website (September 2012) and may represent novel species specifically adapted to coal bed ecosystems. Therefore, further isolation studies from coal beds are needed to better understand indigenous organisms and function. Obtaining additional samples providing analysis of the microbial community along a coal bed flow path in several different areas and identifying how the 
microbial community dynamics change may lead to a better understanding of the differences in the isotopic data observed near the western margin and further into the center of the PRB.

Supplementary data to this article can be found online at http:// dx.doi.org/10.1016/j.coal.2013.03.006.

\section{Acknowledgments}

We would like to thank Kristen Brileya for the help with culturing methods. We are grateful to Elizabeth Meredith, John Wheaton and Clarence Schwartz from the Montana Bureau of Mines and Geology for their help in developing the DMS and providing access to WR-53A. We would also like to thank Donald LaPlant (LaPlant Construction), Tony Seesing (Big Sky Welding) and Ken Anderson for their help in constructing the DMS. This project was supported in part by DOE ZERT Program under grant no. DE-FC26-04NT42262. The development of subsurface sampling techniques and pyrosequencing techniques was supported as a component of ENIGMA, a scientific focus area program supported by the U.S. Department of Energy, Office of Science, Office of Biological and Environmental Research, Genomics: GTL Foundational Science through contract DE-AC02-05CH11231 between Lawrence Berkeley National Laboratory and the U.S. Department of Energy.

\section{References}

Alfreider, A., Krossbacher, M., Psenner, R., 1997. Groundwater samples do not reflect bacterial densities and activity in subsurface systems. Water Research 31, 832-840.

Baker, G.C., Smith, J.J., Cowan, D.A., 2003. Review and re-analysis of domain-specific $16 \mathrm{~S}$ primers. Journal of Microbiological Methods 55, 541-555.

Bates, B.L., McIntosh, J.C., Lohse, K.A., Brooks, P.D., 2011. Influence of groundwater flowpaths, residence times and nutrients on the extent of microbial methanogenesis in coal beds: Powder River Basin, USA. Chemical Geology 284, 45-61.

Bauder, J., 2007. Coal bed methane its promise and problems. Montana's Agenda Issues Shaping Our State, 4 1-4.

Bou-Raad, M., Hobday, M., Rix, C.J., 2000. Aqueous extraction of oxalate and other anions from coal. Fuel 79, 1185-1193.

Bowen De León, K., Ramsay, B.D., Fields, M.W., 2012. Quality-score refinement of SSU rRNA gene pyrosequencing differs across gene region for environmental samples. Microbial Ecology 64, 499-508.

Breznak, J.A., 2002. Phylogenetic diversity and physiology of termite gut spirochetes. Integrative and Comparative Biology 42, 313-318.

Chao, A., Lee, S.-M., 1992. Estimating the number of classes via sample coverage. Journal of the American Statistical Association 87, 210-217.

Edwards, R.A., Rodriguez-Brito, B., Wegley, L., Haynes, M., Breitbart, M., Peterson, D.M., Saar, M.O., Alexander, S., Alexander, E.C., Rohwer, F., 2006. Using pyrosequencing to shed light on deep mine microbial ecology. BMC Genomics 7, 57.

Eichler, B., Schink, B., 1984. Oxidation of primary aliphatic alcohols by Acetobacterium carbinolicum sp. nov., a homoacetogenic anaerobe. Archives of Microbiology 140, 147-152.

Flores, R.M., Rice, C.A., Stricker, G.D., Warden, A., Ellis, M.S., 2008. Methanogenic pathways of coal-bed gas in the Powder River Basin, United States: the geologic factor. International Journal of Coal Geology 76, 52-75.

Fry, J.C., Horsfield, B., Sykes, R., Cragg, B.A., Heywood, C., Kim, G.T., Mangelsdorf, K., Mildenhall, D.C., Rinna, J., Vieth, A., Zink, K.G., Sass, H., Weightman, A.J., Parkes, R.J., 2009. Prokaryotic populations and activities in an interbedded coal deposit, including a previously deeply buried section (1.6-2.3 km) above approx. $150 \mathrm{Ma}$ basement rock. Geomicrobiology Journal 26, 163-178.

Galagan, J.E., Nusbaum, C., Roy, A., Endrizzi, M.G., Macdonald, P., et al., 2002. The genome of $M$. acetivorans reveals extensive metabolic and physiological diversity. Genome Research 12, 532-542.

Green, M.S., Flanegan, K.C., Gilcrease, P.C., 2008. Characterization of a methanogenic consortium enriched from a coalbed methane well in the Powder River Basin, U.S.A. International Journal of Coal Geology 76, 34-45.

Griebler, C., Mindl, B., Slezak, D., Geiger-Kaiser, M., 2002. Distribution patterns of attached and suspended bacteria in pristine and contaminated shallow aquifers studied with an in situ sediment exposure microcosm. Aquatic Microbial Ecology 28, 117-129.

Guo, H., Yu, Z., Liu, R., Zhang, H., Zhong, Q., Xiong, Z., 2012. Methylotrophic methanogenesis governs the biogenic coal bed methane formation in Eastern Ordos Basin, China. Applied Microbiology and Biotechnology 96, 1587-1597.

Haas, B.J., Gevers, D., Earl, A.M., Feldgarden, M., Ward, D.V., Giannoukos, G., Ciulla, D., Tabbaa, D., Highlander, S.K., Sodergren, E., Methé, B., DeSantis, T.Z., Petrosino, J.F., Knight, R., Birren, B.W., 2011. Chimeric 16S rRNA sequence formation and detection in Sanger and 454-pyrosequenced PCR amplicons. Genome Research 21, 494-504.

Huber, J.A., Mark Welch, D.B., Morrison, H.G., Huse, S.M., Neal, P.R., Butterfield, D.A., Sogin, M.L., 2007. Microbial population structures in the deep marine biosphere. Science $318,97-100$
Hughes, J.B., Hellmann, J.J., Ricketts, T.H., Bohannan, B.J.M., 2001. Counting the uncountable: statistical approaches to estimating microbial diversity. Applied and Environmental Microbiology 67, 4399-4406.

Ito, T., Yoshiguchi, K., Ariesyady, H.D., Okabe, S., 2011. Identification of a novel acetateutilizing bacterium belonging to Synergistes group 4 in anaerobic digester sludge. The ISME Journal 5, 1844-1856.

Jones, E.J.P., Voytek, M.A., Corum, M.D., Orem, W.H., 2010. Stimulation of methane generation from nonproductive coal by addition of nutrients or a microbial consortium. Applied and Environmental Microbiology 76, 7013-7022.

Jonsson, S., Ricagno, S., Lindqvist, Y., Richards, N.G.J., 2004. Kinetic and mechanistic characterization of the formyl-CoA transferase from Oxalobacter formigenes. The Journal of Biological Chemistry 279, 36003-36012.

Klein, D.A., Flores, R.M., Venot, C., Gabbert, K., Schmidt, R., Stricker, G.D., Pruden, A. Mandernack, K., 2008. Molecular sequences derived from Paleocene Fort Union Formation coals vs. associated produced waters: implications for CBM regeneration. International Journal of Coal Geology 76, 3-13.

Leadbetter, J.R., Schmidt, T.M., Graber, J.R., Breznak, J.A., 1999. Acetogenesis from $\mathrm{H}_{2}$ plus $\mathrm{CO}_{2}$ by spirochetes from termite guts. Science $283,686-689$.

Li, D., Hendry, P., Faiz, M., 2008. A survey of the microbial populations in some Australian coalbed methane reservoirs. International Journal of Coal Geology 76, 14-24.

Luton, P.E., Wayne, J.M., Sharp, R.J., Riley, P.W., 2002. The mcrA gene as an alternative to 16S rRNA in the phylogenetic analysis of methanogen populations in landfill. Microbiology 148, 3521-3530.

Meredith, E., Wheaton, J., Kuzara, S., 2012. Coalbed-methane basics ten years of lessons from the Powder River Basin. Information Pamphlet, 6. Montana Bureau of Mines and Geology.

Midgley, D.J., Hendry, P., Pinetown, K.L., Fuentes, D., Gong, S., Mitchell, D.L., Faiz, M. 2010. Characterisation of a microbial community associated with a deep, coal seam methane reservoir in the Gippsland Basin, Australia. International Journal of Coal Geology 82, 232-239.

Mochimaru, H., Uchiyama, H., Yoshioka, H., Imachi, H., Hoaki, T., Tamaki, H., Nakamura, K., Sekiguchi, Y., Kamagata, Y., 2007. Methanogen diversity in deep subsurface gasassociated water at the Minami-Kanto Gas Field in Japan. East 24, 93-100.

Peacock, A.D., Chang, Y.J., Istok, J.D., Krumholz, L., Geyer, R., Kinsall, B., Watson, D., Sublette, K.L., White, D.C., 2004. Utilization of microbial biofilms as monitors of bioremediation. Microbial Ecology 47, 284-292.

Penner, T.J., Foght, J.M., Budwill, K., 2010. Microbial diversity of western Canadian subsurface coal beds and methanogenic coal enrichment cultures. International Journal of Coal Geology 82, 81-93.

Reardon, C.L., Cummings, D.E., Petzke, L.M., Kinsall, B.L., Watson, D.B., Peyton, B.M Geesey, G.G., 2004. Composition and diversity of microbial communities recovered from surrogate minerals incubated in an acidic uranium-contaminated aquifer. Applied and Environmental Microbiology 70, 6037-6046.

Rice, C.A., Flores, R.M., Stricker, G.D., Ellis, M.S., 2008. Chemical and stable isotopic evidence for water/rock interaction and biogenic origin of coalbed methane, Fort Union Formation, Powder River Basin, Wyoming and Montana U.S.A. International Journal of Coal Geology 76, 76-85.

Rotaru, A.-E., Probian, C., Wilkes, H., Harder, J., 2010. Highly enriched Betaproteobacteria growing anaerobically with p-xylene and nitrate. Fems Micriobiology Ecology $71,460-468$.

Schlüter, A., Bekel, T., Diaz, N.N., Dondrup, M., Eichenlaub, R., Gartemann, K.-H., Krahn, I., Krause, L., Krömeke, H., Kruse, O., Mussgnug, J.H., Neuweger, H., Niehaus, K. Pühler, A., Runte, K.J., Szczepanowski, R., Tauch, A., Tilker, A., Viehöver, P., Goesmann, A., 2008. The metagenome of a biogas-producing microbial community of a production-scale biogas plant fermenter analysed by the 454-pyrosequencing technology. Journal of Biotechnology 136, 77-90.

Shimizu, S., Akiyama, M., Naganuma, T., Fujioka, M., Nako, M., Ishijima, Y., 2007. Molecular characterization of microbial communities in deep coal seam groundwater of northern Japan. Geobiology 5, 423-433.

Strąpoć, D., Picardal, F.W., Turich, C., Schaperdoth, I., Macalady, J.L., Lipp, J.S., Lin, Y.-S. Ertefai, T.F., Schubotz, F., Hinrichs, K.-U., Mastalerz, M., Schimmelmann, A., 2008. Methane-producing microbial community in a coal bed of the Illinois Basin. Applied and Environmental Microbiology 74, 2424-2432.

Strapoć, D., Mastalerz, M., Dawson, K., Macalady, J., Callaghan, A.V., Wawrik, B., Turich, C., Ashby, M., 2011. Biogeochemistry of microbial coal-bed methane. Annual Review of Earth and Planetary Sciences 39, 617-656.

Unal, B., Perry, V.R., Sheth, M., Gomez-Alvarez, V., Chin, K.-J., Nüsslein, K., 2012. Trace elements affect methanogenic activity and diversity in enrichments from subsurface coal bed produced water. Frontiers in Microbiology 3, 175.

Van Voast, W., Thale, P., 2001. Anderson and Knobloch coal horizons and potential for methane development, Powder River Basin, Montana: Montana Bureau of Mines and Geology Geologic Map 60, 1 sheet.

Walker, C.B., He, Z., Yang, Z.K., Ringbauer, J.A., He, Q., Zhou, J., Voordouw, G., Wall, J.D., Arkin, A.P., Hazen, T.C., Stolyar, S., Stahl, D.A., 2009. The electron transfer system of syntrophically grown Desulfovibrio vulgaris. Journal Of Bacteriology 191, 5793-5801.

Wheaton, J.R., Donato, T., 2004. Ground-water monitoring program in prospective coalbed-methane areas of Southeastern Montana: year one. Montana Bureau of Mines and Geology Open-File MBMG, 508.

Yakimov, M.M., Giuliano, L., Chernikova, T.N., Gentile, G., Abraham, W.R., Lunsdorf, H., Timmis, K.N., Golyshin, P.N., 2001. Alcalilimnicola halodurans gen. nov., sp nov., an alkaliphilic, moderately halophilic and extremely halotolerant bacterium, isolated from sediments of soda-depositing Lake Natron, East Africa Rift Valley. International Journal of Systematic and Evolutionary Microbiology 51, 2133-2143. 